Am. J. Nephrol. 1985;5:476

\title{
Carpal Tunnel Syndrome and Chronic Hemodialysis
}

\section{Dear Sir,}

Referring to the letter by Walts et al. [1] published in your journal, our work is at odds with theirs.

In our clinic we have monitored 176 patients in a program of chronic hemodialysis for periods ranging from 3 to 144 months $(x=67.6)$. Eight patients ( 3 male and 5 female) manifested carpal tunnel syndrome (CTS); their ages ranged from 40 to 81 years $(\mathrm{x}=61.1)$. The duration of dialysis treatment was 91.5 months (range 72-144). These results contrast with the 176 months (14.7 years) that the said authors [1] speak of. Our work coincides with previously reviewed literature [2-5]. In 5 of these cases the syndrome was bilateral and in 3 unilateral (a total of 13 occurrences). In each case it was the arm with a functioning arteriovenous fistula which was affected; given that this was the sole vascular access no further surgical intervention was required.

We pursued 5 anatomopathological studies with Congo red and thioflavine T manifesting a total of 9 interventions (8 patients). In only 1 case did we find deposits of amyloid. None of the affected patients presented indices of systemic amyloidosis. In the development of CTS, the patients in a program of chronic hemodialysis showed a marked preference for the arm carrying the vascular access despite the fact that neither vascular alterations nor inflammatory changes were noted in the anatomopathological studies effected.

We observed no statistically significant relation with any special type of nephropathy such as presented by our patients: hyperuricemic nephropathy (2 cases), glomeru-lonephritis (2 cases), nephroangiosclerosis (1 case, showing the only incidence of amyloid deposits), tubular aci-dosis (1 case) and undefined etiologies (2 cases). Nor was any relation observed with the dialytic procedure, hyper-

volemia, or the various biochemical parameters studied (urea, creatinine, phosphocalcic metabolism, PTH and hematocrit count).

According to our experience, CTS is a complication of periodic hemodialysis that does not show an elevated incidence of amyloid deposits, and in general appears after the sixth year of substitutive treatment.

\section{References}

Walts, A.E.; Goodman, M.D.; Matorin, P.A.: Amyloid, carpal tunnel syndrome, and chronic hemodialysis. Am. J. Nephrol. 5: 225-226 (1985).

Halter, S.K.; DeLisa, J.A.; Stolov, W.C; Scardapane, D.; Sher-rard, D.J.: Carpal tunnel syndrome in chronic renal dialysis patients. Archs phys. Med. Rehabil. 62: 197-201 (1981).

Schwarz, A.; Keller, F.; Seyfert, S.; Poll, W.; Molzahn, M.; Dist-ler, A.: Carpal tunnel syndrome: a major complication in long-term hemodialysis patients. Clin. Nephrol. 22: 133-137 (1984). Kachel, H.G.; Altmeyer, P.; Baldamus, C.A.; Koch, K.M.: Deposition of an amyloid-like substance as a possible complication of regular dialysis treatment. Contr. Nephrol. vol. 36, pp. 127-132 (Karger, Basel 1983). 
Spertini, F.; Wauters, J.P.; Poulenas, I.: Carpal tunnel syndrome: a frequent, invalidating, longterm complication of chronic hemodialysis. Clin. Nephrol. 21: 98-101 (1984).

J. Martinez, P. Forts, J. Falgás, E. Martinez, I. Mascort, 